https://helda.helsinki.fi

pÿRome s World: The Peutinger Map Reconsidered,

\author{
Mataix Ferrándiz, Emilia
}

2017

pÿMataix Ferrándiz , E 2017 , ' Rome s World: The Peutinger Map Reconsidered, ' , Masaq , vol. 29 , no. 1 .

http://hdl.handle.net/10138/312100

acceptedVersion

Downloaded from Helda, University of Helsinki institutional repository.

This is an electronic reprint of the original article.

This reprint may differ from the original in pagination and typographic detail.

Please cite the original version. 


\section{Rome's World: The Peutinger Map Reconsidered}

Richard J. A. Talbert, 2010

Cambridge; New York: Cambridge University Press,

Pp. xviii, 357

$£ 29.99$ / \$44.99 (paperback)

ISBN 9780521764803.

Emilia Mataix Ferrándiz, University of Southampton (Portus Limen project)

E.Mataix-ferrandiz@soton.ac.uk

The Peutinger map (PM) or Tabula Peutingeriana (as referred to by Talbert) is an incomplete map of the Roman world, conserved in the Austrian National library, which includes an elaborate network of routes. It is formed of eleven single parchment segments, designed to be joined together side by side to create a long ribbon. The work of Richard Talbert (RT) constitutes the first full book in English dealing with the features, context and history of the $\mathrm{PM}^{1}$. Following this, other books dealing with the map as a medieval artefact have also been published $^{2}$, completing and sometimes challenging the work of RT. According to RT, the PM, produced around A.D. 1200, is a copy of a lost original dating to the era of Diocletian's tetrarchy (ca. A.D. 300).

The book is composed of an introduction, five chapters, one conclusion, nine appendices, endnotes, bibliography, an index and a gazetteer. The book contains several illustrations (especially in chapter 5) which help to contextualize and give a better understanding of the PM. Other important additions to the book are the digital material - in particular, a dynamic map viewer published online which allows the user to zoom, navigate and overlay additional details onto the map's layers ${ }^{3}$. Talbert is the author of the Barrington Atlas of the Greek and Roman World (Princeton 2000) and a leading expert on ancient cartography. Following the example of his former work, RT has made a great contribution to the scholarship with his digital reconstruction of the map, which includes comments on all the names and features on the map and an outline of rivers and routes.

In the introduction (pp.1-9), RT openly affirms that the original map was part of a decorative scheme for a public space inside an imperial palace of the Tetrarchic period

\footnotetext{
${ }^{1}$ For other examples, see: Konrad Miller. Itineraria Romana. Römische Reisewege an Der Hand Der Tabula Peutingeriana (Verlegt von strecker und Schroder in Stuttgart, Stuttgart, 1916); Annalisa Levi / Mario Levi. Itineraria picta. Contributo allo studio della Tabula peutingeriana (Roma, L' erma di Bretschneider, 1967).

${ }^{2}$ Emily Albu. The Medieval Peutinger Map: Imperial Roman Revival in a German Empire. Cambridge University Press, 2014.

${ }^{3} \mathrm{http}: / /$ peutinger.atlantides.org/map-a/
} 
(around AD 300). This view challenges a former approach, which asserted that this map was just created for practical purposes (Miller: 1916). Moreover, RT asserts that this is a map without any close match in any period or culture worldwide - he demonstrates this in his conclusion by placing it in relation to Classical cartography and comparing it to other medieval examples. Furthermore, RT affirms that the map's innovative design and content made a widespread impact that continued to be felt for many centuries.

In the first chapter (pp. 10-72), RT reviews the history of the PM, which was discovered by Conrad Celtis around 1500 and bequeathed to Peutinger. RT refers to the various publications of the PM and about the Codex Vindobonensis 324 (how it is labelled in the Austrian National Library). What seems clear is that despite its precious value, the PM remained neglected and was presumed lost during the $17^{\text {th }}$ century. $R T$ refers to the scholars who worked on the map in order of their importance and not just by chronology. He reviews succinctly the systematic approaches to the PM during the $18^{\text {th }}$ and $19^{\text {th }}$ centuries (von Scheyb's, Mannert, Vodnik, Cristianopoulo, Katancisch, Fortia d' Urban and Desjardins) until arriving at the publication of Konrad Miller's edition (1916). RT discusses that publication, indicating that it is the last systematic presentation of the PM. The author refers briefly to the works focused on the PM after Miller's text (i.e. Cuntz, Bosio), concluding that these studies do not prevent the need for a fresh approach as the present study is trying to achieve.

Chapter two ${ }^{4}$ (pp. 73-85) approaches the PM under a material and paleographic scope. Some remarkable features are that the pieces which compose the map seem to have been glued and not sewn (that constituted a common medieval practice), that the map has holes at its sides (which may indicate that it was exposed), and that the inks employed have proven to be very resilient (they have not been restored before). The revision of the scripts indicates that the map was copied layer by layer, and the drawings display an idiosyncratic approach, depicting the big cities with symbols. The evidence suggests that the copy was produced between the end of the twelfth century and beginning of the thirteenth, and that it was produced by a single individual (an artist) in the south German region or even Alsace.

The third chapter (pp. 86-122) considers the essential traits of the map' s design, the mapmaking practice that it reflects, and the map's various physical and cultural components, specially focusing on the route network and its associated pictorial symbols. The analysis of these features of the map have been done upon the unverifiable assumption of RT that this surviving copy of the map represents a sufficiently accurate rendering of the lost original to reconstruct it just through the study of the copy alone.

Chapter four (pp. 123-132) addresses the issue of understanding how accurate the copy of the map can be reckoned to reconstruct the original. RT undertakes that by analysing

\footnotetext{
${ }^{4}$ With the collaboration of Martin Steinmann
} 
three means: copyists' initiatives; names and figures and route and line work. In a final section, RT summarizes copyists' flaws in perspective, highlighting the difficulty of the task accomplished by the copyists of the map. The main aim of the copyists was to reproduce all the PM elements faithfully, even if they compromised some of the lettering, symbols and route line work.

Chapter five (pp. 133-157) no longer focuses on the surviving copy of the map but turns to the lost original, addressing authorship; date; sources; context and purpose. RT points out that a team is the most likely maker of the map, and convincingly argues that the outline and elements composing the map ${ }^{5}$ underline that its use was decorative and not a practical resource to be used by travellers. Moreover, RT thinks that the map's features (which show evidence of the artistic taste of the $4^{\text {th }}$ century) point to the fact the original would have best fit into an apse of an imperial reception hall. In fact, RT thinks that the map can be associated with the group of signa imperii unhearthed in an official excavation (2005) on Rome's Palatine hill. However, RT warns that his suggestions on all these issues are speculative. This chapter ends with an array of charts displaying a comparative listing of routes in Italy by the PT, Bordeaux itinerary and the Antonine itinerary (pp. 158-161).

In the concluding chapter (pp. 162-172), RT tackles three characteristics of the map in the context of classical cartography: its unusual shape; its positioning of Rome at the centre; and, as a unique feature of a classical map of the world, the network of routes. RT refers to other examples which display similar elements to the PM, to affirm that the style of such maps was possibly influenced by that of the PM. These examples are maps found in the Ravenna cosmography, another plan found in the commentary on the apocalypse by Beatus, a sketched version by the Italian humanist Prisciani (15th cent.), and the medieval Gough map of Great Britain $^{6}$. In conclusion, RT affirms that the PM embodies a transition of mapmaking between Classical and medieval cartography, thus being much more than a simple route diagram.

The book ends with nine appendices (pp. 173-286) which provide further materials as translations and commentaries regarding of the Peutinger map (app. 1-6) and in part offer users' guides to the online content available - not just of the digitalised edition of the PT (app. 7-8) but also the Barrington atlas bases (app. 9).

Even if the assertions of RT concerning the PM are - in his own words - speculative, the author manages to set a new and fresh approach to the map. His analysis of the stylistic elements, appealing for $4^{\text {th }}$ century intellectual taste in art (p. 153), contrasts with the previously asserted primary practical scope of the map. The chapters describing RT

\footnotetext{
${ }^{5}$ Like the central placement of Rome in the map (not giving special importance to the new Tetrarchic capitals), or the inclusion of places and routes which do not cohere chronologically.

6 For more information about it and consult the digitalised copy of the map, see http://www.goughmap.org/about/
} 
arguments on the map, together with the digital contents available, shape a rich edition of the Peutingerian map that will lead to further research and scholarly interest in the future. 